\title{
Atomic Force Microscopy as a Tool for the Investigation of Cellular Cytoplasmic Membrane Dynamics
}

\author{
Glenn Fried*, Stanislav Rubakhin**, Jonathan Sweedler** \\ * Imaging Technology Group Beckman Institute of Technology University of Illinois at \\ Urbana Champaign \\ ** Department Of Chemistry University of Illinois at Urbana Champaign
}

In the past cytoplasmic membrane movement in living cells have been primarily measure using optical techniques. The limitations of these methods result from a lack of contrast and resolution inherent to optical techniques. To overcome these problems Atomic Force Microscopy (AFM) has been used to detect cytoplasmic membrane movement. In our work Aplysia californica neurons were observed on the millisecond to hour time frame. Results from these measurements show nanometer scale spatial resolution and millisecond temporal resolution.

Cells were cultured on CELLocate 5245 disks in artificial seawater for one day. The $\mathrm{O}$ ring for the nanoscope IIIa liquid cell, coated with grease is placed on the disk before it is removed from the culture dish; this preserved the aqueous environment for the living cells during transportation to the AFM. A gravity profusion apparatus was used which both supplied a gentle continues flow and prevented bubbles from entering the chamber. AFM tips were made by gluing a $2 \mu \mathrm{m}$ to $5 \mu \mathrm{m}$ sphere to a tipples cantilever ${ }^{2}$ using epoxy. Typical force constants were $0.06 \mathrm{~N} / \mathrm{m}$. The forces on the cell was maintained below $20 \mathrm{nN}$ and dispersed over the contact area of the sphere and the cell.

Challenging the cell with an osmolarity change to the cell surroundings can trigger cytoplasm membrane movement. It is generally accepted that an osmalaiity change in the extra cellular environment results in auquaporin mediated water transport through the cell wall forcing a change in the volume of the cell and a measurable movement of the cell membrane ${ }^{3}$. We have used this method to compare the affects of sucrose induced extra cellular osmolarity changes (Fig 3,4,5) and the affect of sucrose induced osmolarity changes in the presents of digitonen. Comparison of artificial and biological fluids has also been demonstrated.

\section{References}

1 Zhang PC, Keleshian AM, and Sachs F Nature vol $4132001428-432$

2 purchased from Digital Instruments. Santa Barbara CA

3Venero JL, Vizuete ML, Machado A, Cano J Progress in Neurobiology vol 632001 321-336 


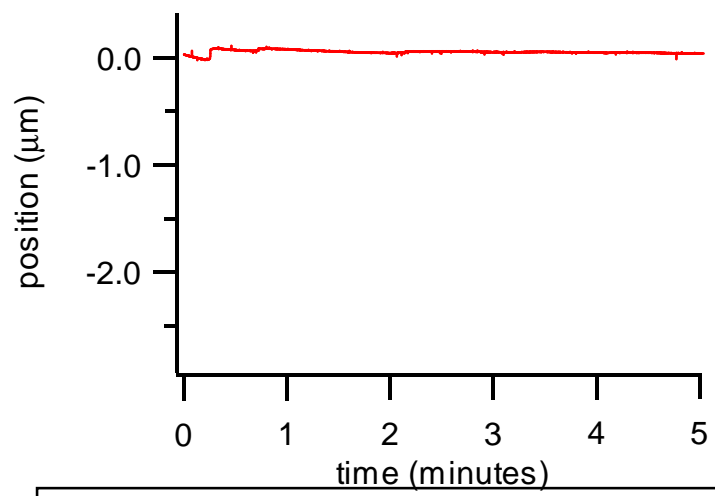

Fig 1 Continues measurement on the surface of the cover slip

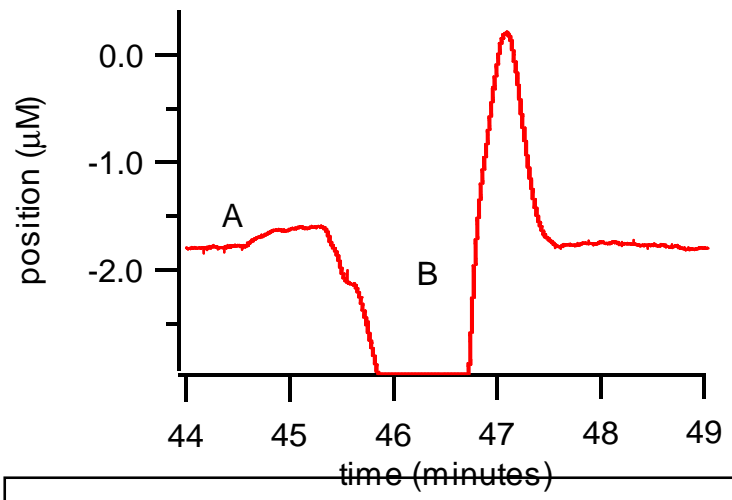

Fig 3 Measurement during osmolarity change, sucrose concentration was increased $10 \%$ at point $\mathrm{A}$ and decreased to original concentration at point $\mathrm{B}$.

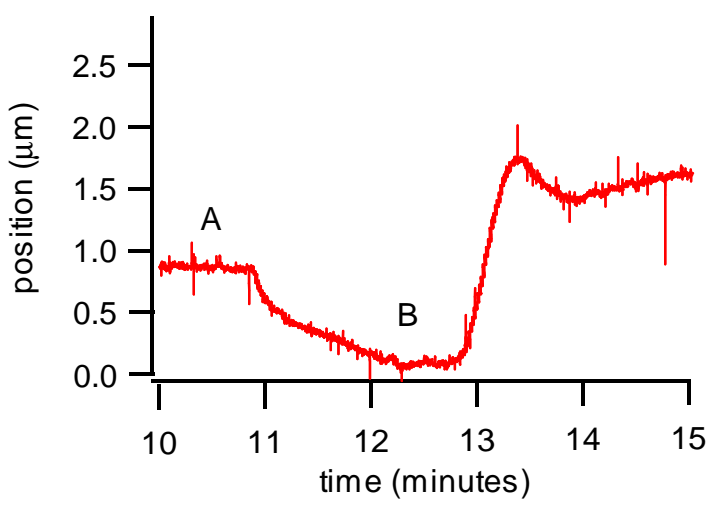

Fig 5 Measurement during osmolarity change, sucrose concentration was increased $1 \%$ at point $\mathrm{A}$ and decreased to original concentration at point $\mathrm{B}$.

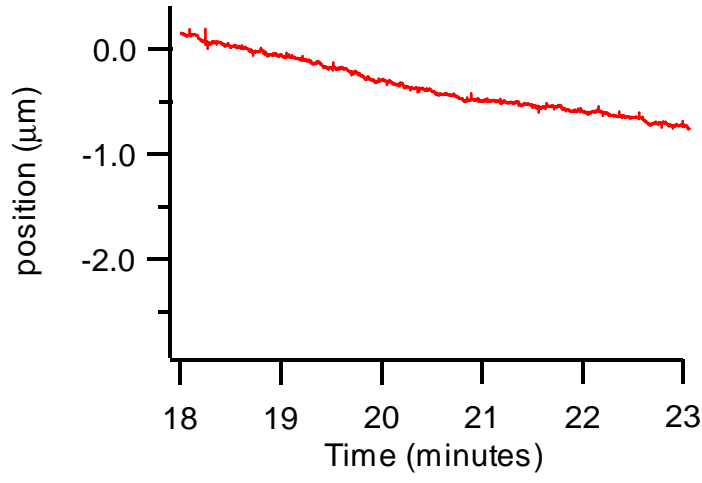

Fig. 2 Continues measurement on the surface of a live cell with no stimulus.

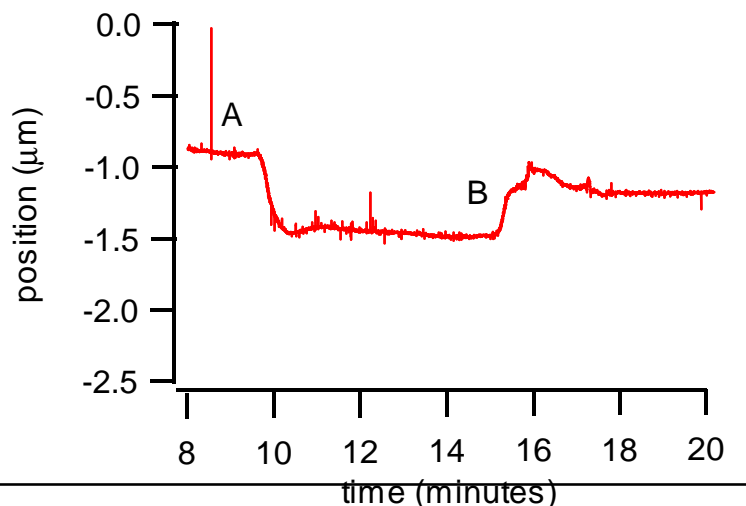

Fig 4 Measurement during osmolarity change, sucrose concentration was increased $10 \%$ in the presents of digitonen at point $\mathrm{A}$ and decreased to original concentration at point $\mathrm{B}$.

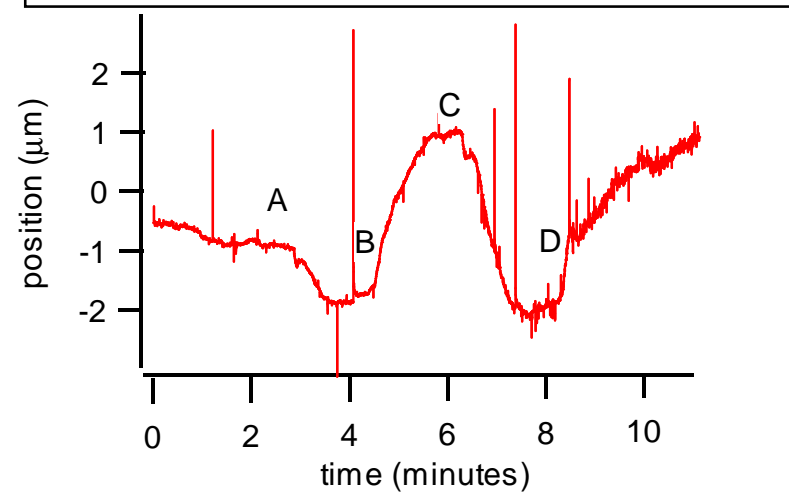

Fig. 6 Hemolymph from animal 1 introduced at point $\mathrm{A}$, Washed at point $\mathrm{B}$, Hemolyph from animal 2 introduced at point $\mathrm{C}$, washed at point $\mathrm{D}$. 